\title{
Environmental Fluctuations in Forward Scatter and Reverberation
}

\author{
W.S. Hodgkiss \\ Marine Physical Laboratory \\ Scripps Institution of Oceanography \\ La Jolla, CA 92093-0701 \\ phone: (858) 534-1798 / fax: (858) 822-0665 \\ email: whodgkiss@ucsd.edu
}

Award Number: N00014-12-1-0513

http://www.mpl.ucsd.edu

\section{LONG-TERM GOALS}

Conduct field experiments, data analyses, and modeling exploring the impact of environmental fluctuations on forward scatter and reverberation as well as on the inversion for seafloor geoacoustic parameters.

\section{OBJECTIVES}

Measure fluctuations in mid-frequency $(\sim 1-10 \mathrm{kHz})$ shallow water forward scatter and reverberation due to time-evolving variability in the sea surface and water column environment as well as source motion. Use observations to quantify the uncertainty in seafloor geoacoustic inversions due to environmental variability and their subsequent use in reverberation level predictions.

\section{APPROACH}

The focus of this research is on understanding the relationship between fluctuations in mid-frequency $(\sim 1-10 \mathrm{kHz})$ shallow water forward scatter and reverberation due to time-evolving variability in the sea surface and water column environment as well as source motion. In addition, the impact of environmental variability on the uncertainty in mid-frequency seafloor geoacoustic inversions and their subsequent use in reverberation level predictions is of interest. A major component of this project has been participation in the planning and execution of the ONR Target and Reverberation Experiment 2013 (TREX13) which was carried out in April-May 2013 off Panama City, FL.

The reverberation field experiment provided an opportunity to make concurrent environmental and mid-frequency acoustic observations that will facilitate data analysis related to the following objectives: (1) understand the relationship between fluctuations in shallow water forward scatter and reverberation and the time-evolving variability in the sea surface and water column environment, (2) understand the relationship between fluctuations in forward scatter and reverberation and source motion over a heterogeneous seafloor, and (3) quantify the uncertainty in mid-frequency seafloor geoacoustic inversions due to environmental variability and their subsequent use in reverberation level predictions.

The following measurements were included as part of the field experiment and are of interest to various investigators. 


\section{Report Documentation Page}

Form Approved

OMB No. 0704-0188

Public reporting burden for the collection of information is estimated to average 1 hour per response, including the time for reviewing instructions, searching existing data sources, gathering and maintaining the data needed, and completing and reviewing the collection of information. Send comments regarding this burden estimate or any other aspect of this collection of information,

including suggestions for reducing this burden, to Washington Headquarters Services, Directorate for Information Operations and Reports, 1215 Jefferson Davis Highway, Suite 1204, Arlington

VA 22202-4302. Respondents should be aware that notwithstanding any other provision of law, no person shall be subject to a penalty for failing to comply with a collection of information if it

does not display a currently valid OMB control number.

1. REPORT DATE

30 SEP 2014

4. TITLE AND SUBTITLE

Environmental Fluctuations in Forward Scatter and Reverberation

6. $\operatorname{AUTHOR}(\mathrm{S})$

7. PERFORMING ORGANIZATION NAME(S) AND ADDRESS(ES)

University of California San Diego,Scripps Institution of Oceanography,9500 Gilman Drive,La Jolla,CA,92093

9. SPONSORING/MONITORING AGENCY NAME(S) AND ADDRESS(ES)

3. DATES COVERED

00-00-2014 to 00-00-2014

5a. CONTRACT NUMBER

5b. GRANT NUMBER

5c. PROGRAM ELEMENT NUMBER

5d. PROJECT NUMBER

5e. TASK NUMBER

5f. WORK UNIT NUMBER

8. PERFORMING ORGANIZATION

REPORT NUMBER

10. SPONSOR/MONITOR'S ACRONYM(S)

11. SPONSOR/MONITOR'S REPORT

NUMBER(S)

12. DISTRIBUTION/AVAILABILITY STATEMENT

Approved for public release; distribution unlimited

13. SUPPLEMENTARY NOTES

14. ABSTRACT

15. SUBJECT TERMS

16. SECURITY CLASSIFICATION OF:

a. REPORT

unclassified b. ABSTRACT

unclassified c. THIS PAGE

unclassified
17. LIMITATION OF ABSTRACT

Same as

Report (SAR)
18. NUMBER 19a. NAME OF

OF PAGES RESPONSIBLE PERSON

5

Standard Form 298 (Rev. 8-98) Prescribed by ANSI Std Z39-1 


\section{Fluctuations in forward scatter and reverberation}

One area of particular interest is the evolution of mid-frequency vertical spatial coherence as a function of range from the source. In order to understand the physics of multiple forward scatter and backscatter (reverberation), vertical array measurements of the forward propagating field across the water column were carried out in TREX13.

\section{Fluctuations due to source motion over a heterogeneous seafloor}

Along with a time-evolving water column and a dynamic sea surface resulting in fluctuations in the observed forward scatter and reverberation, source movement over a heterogeneous seafloor also will result in fluctuations in the scatter. Source tows over the well-characterized seafloor region were carried out in TREX13.

\section{Uncertainty in mid-frequency seafloor geoacoustic inversions}

Direct measurements of seafloor geoacoustic parameters were carried out at the TREX13 site. The data collected in the fixed source - fixed receiving array and source tow portions of the field experiment can be used to quantify the uncertainty in mid-frequency seafloor geoacoustic inversions due to environmental variability and their subsequent use in reverberation level predictions.

\section{WORK COMPLETED}

The ONR Target and Reverberation Experiment 2013 (TREX13) was carried out in $20 \mathrm{~m}$ deep water off Panama City, FL [1]. The Marine Physical Laboratory (MPL) participated at-sea aboard the R/V Walton Smith over the period 21 April - 11 May 2013 [2]. Three, 32-element (0.2 m element spacing), vertical line arrays (VLAs) were deployed along the Main Reverberation Track at ranges of 0.5, 2.4, and $4.2 \mathrm{~km}$ from the moored source, fixed horizontal line array (HLA), and support ship (R/V Sharp). In addition, 16 self-recording temperature loggers were attached to two of the VLAs. Source tows and stations were carried out by MPL on 22-24 April 2013 with tonal and LFM transmissions covering the $1.5-4.0 \mathrm{kHz}$ and $4.5-9.0 \mathrm{kHz}$ bands.

Analysis of the TREX13 experiment data this past year has focused on the source tow transmissions along the Main Reverberation Track. Specifically, transmission loss (TL) from the towed source to VLA2 has been analyzed.

\section{RESULTS}

The TREX13 geometry is shown in Fig. 1 including the locations of the R/V Sharp and two of the three vertical line arrays (VLA1 and VLA2). VLA3 was located $0.5 \mathrm{~km}$ from the R/V Sharp along the Main Reverberation Track. The source tow track Reverb Track 02 is shown in Fig. 2 along with the Main Reverberation Track bathymetry and locations of vertical arrays VLA1 and VLA2. The map has been rotated from Fig. 1 so that the horizontal axis is along the centerline of the Main Reverberation Track.

An estimate of transmission loss (TL) was made from analysis of the towed source $1.5-4.0 \mathrm{kHz}$ tonal transmissions received on the middle hydrophone of VLA2. The transmissions were $15 \mathrm{~s}$ on, $15 \mathrm{~s}$ off (50\% duty cycle). The average received level over a $15 \mathrm{~s}$ transmission interval was subtracted from the 
source level to estimate TL. These estimates are shown in Figs. 3 and 4 for the outbound and inbound portions of the tow track, respectively. At CPA (range $\sim 200 \mathrm{~m}$ ), the TL varies $\sim 30-40 \mathrm{~dB}$. At the start/end of the tow track (range $\sim 4 \mathrm{~km}$ ), the TL varies $\sim 55-70 \mathrm{~dB}[3]$.

\section{IMPACT / APPLICATIONS}

The mid-frequency band $(\sim 1-10 \mathrm{kHz})$ is used by many systems of interest to the navy including active surface ship sonars, mine-countermeasure (MCM) systems, and acoustic communications. Backscatter (reverberation) frequently limits the performance of active sonar and MCM systems and incoherent forward scatter can inhibit acoustic data communications.

\section{RELATED PROJECTS}

The planning and execution of TREX13 was a joint effort between several ONR Code 322OA investigators interested in various aspects of mid-frequency forward scatter, reverberation, and the inversion of seafloor geoacoustic parameters.

\section{REFERENCES}

[1] T. Hefner, “TREX13 Experiment Test Plan Rev 1.58," Applied Physics Laboratory, University of Washington, 7 April 2013 (2013).

[2] W.S. Hodgkiss, "Target and Reverberation Experiment 2013 (TREX13): MPL Trip Report," Marine Physical Laboratory, Scripps Institution of Oceanography, 13 July 2013 (2013).

[3] W.S. Hodgkiss, D.E. Ensberg, and D.J. Tang, "Propagation measurement using source tow and moored vertical line arrays during TREX13," $168^{\text {th }}$ Meeting of the Acoustical Society of America (27-31 October 2014). 

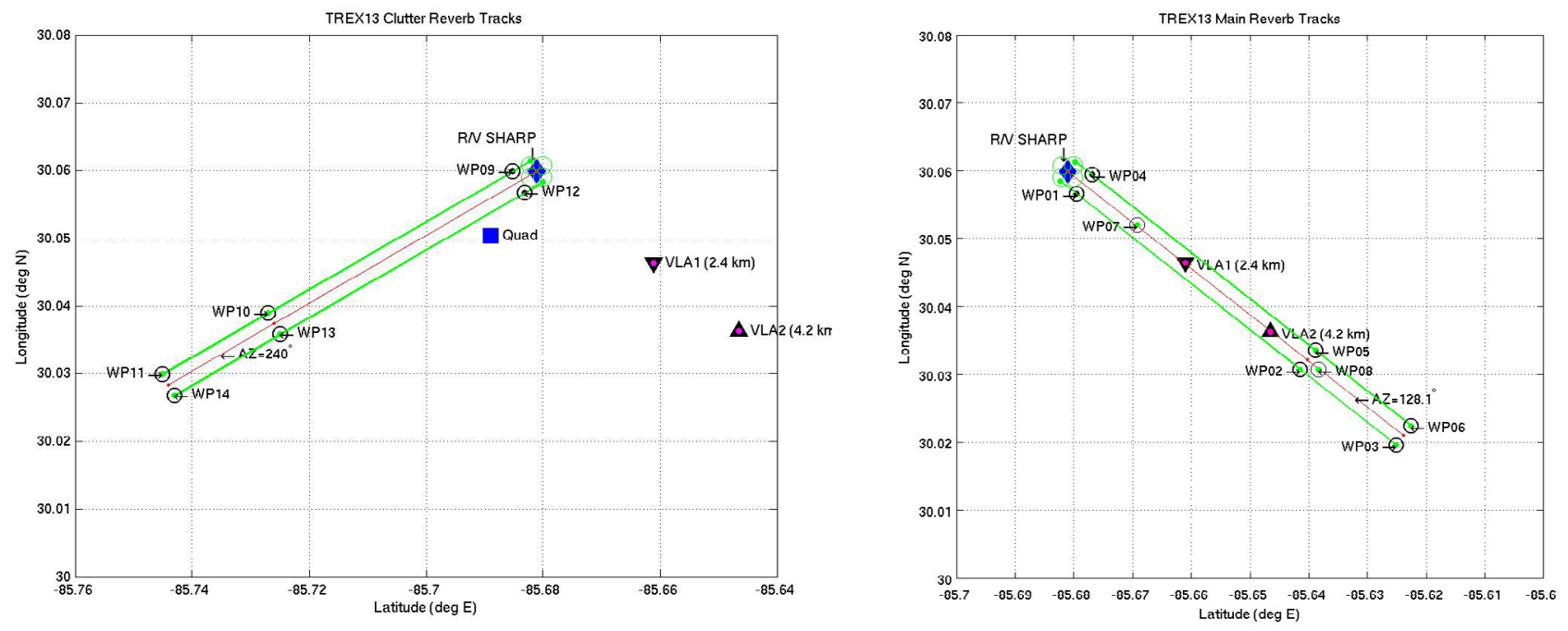

Figure 1. TREX13 geometry including the location of the $R / V$ Sharp and two of the three vertical line arrays (VLAs). (Left) Clutter Reverberation Track. (Right) Main Reverberation Track.

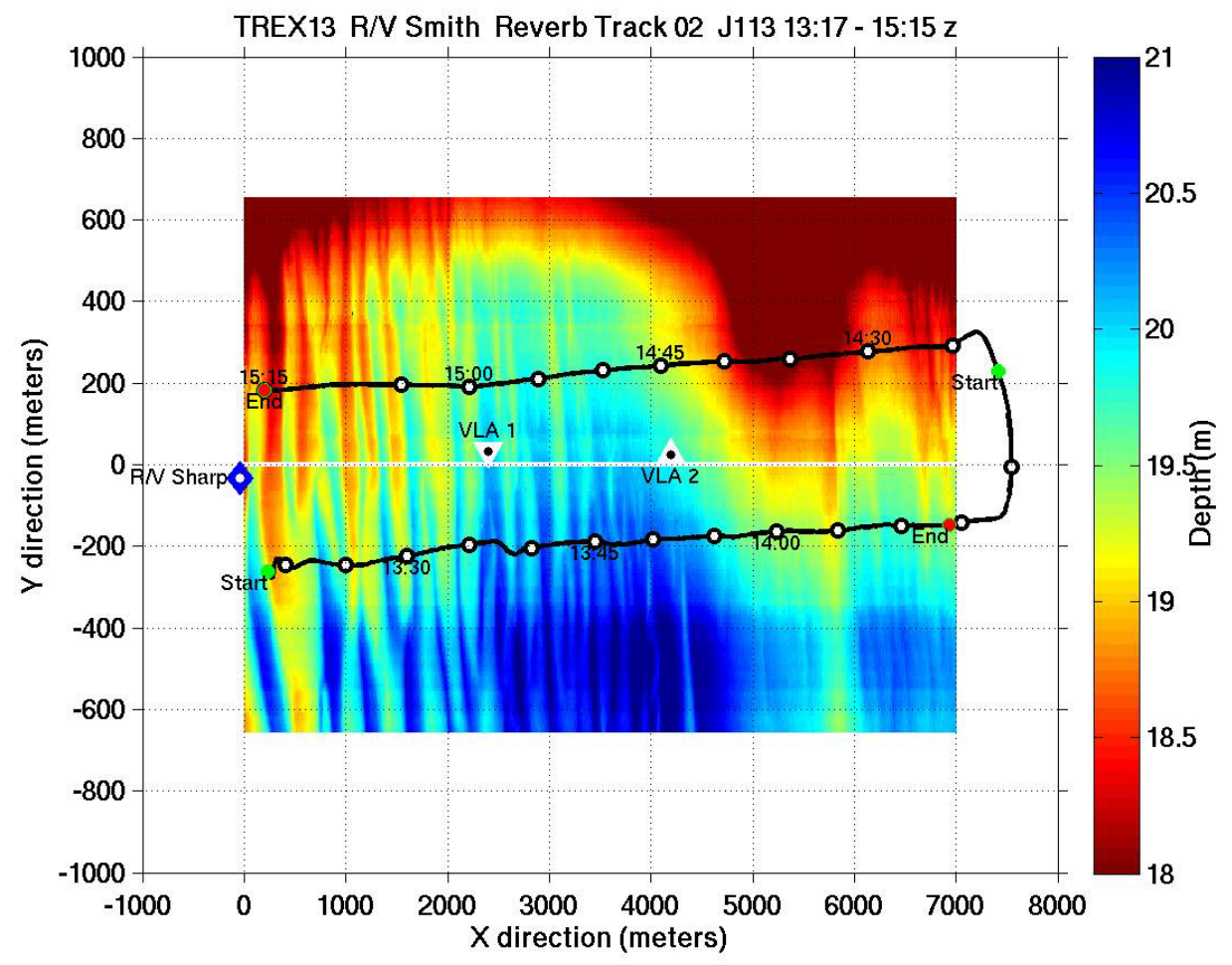

Figure 2. Source tow track Reverb Track 02 along with the Main Reverberation Track bathymetry and locations of vertical arrays $V L A 1$ and $V L A 2$. 


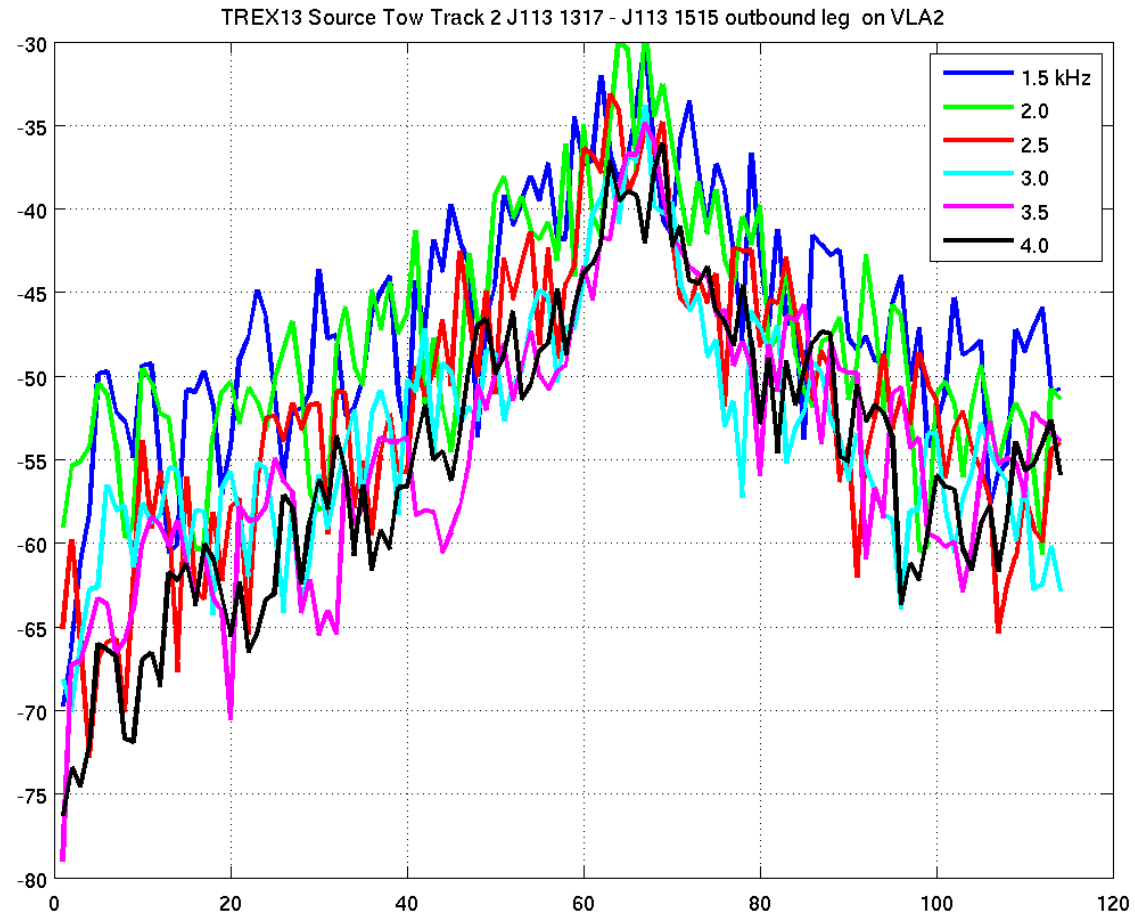

Figure 3. Transmission loss (dB) along outbound leg of source tow track Reverb Track 02. Horizontal axis is in increments of $30 \mathrm{~s}$.

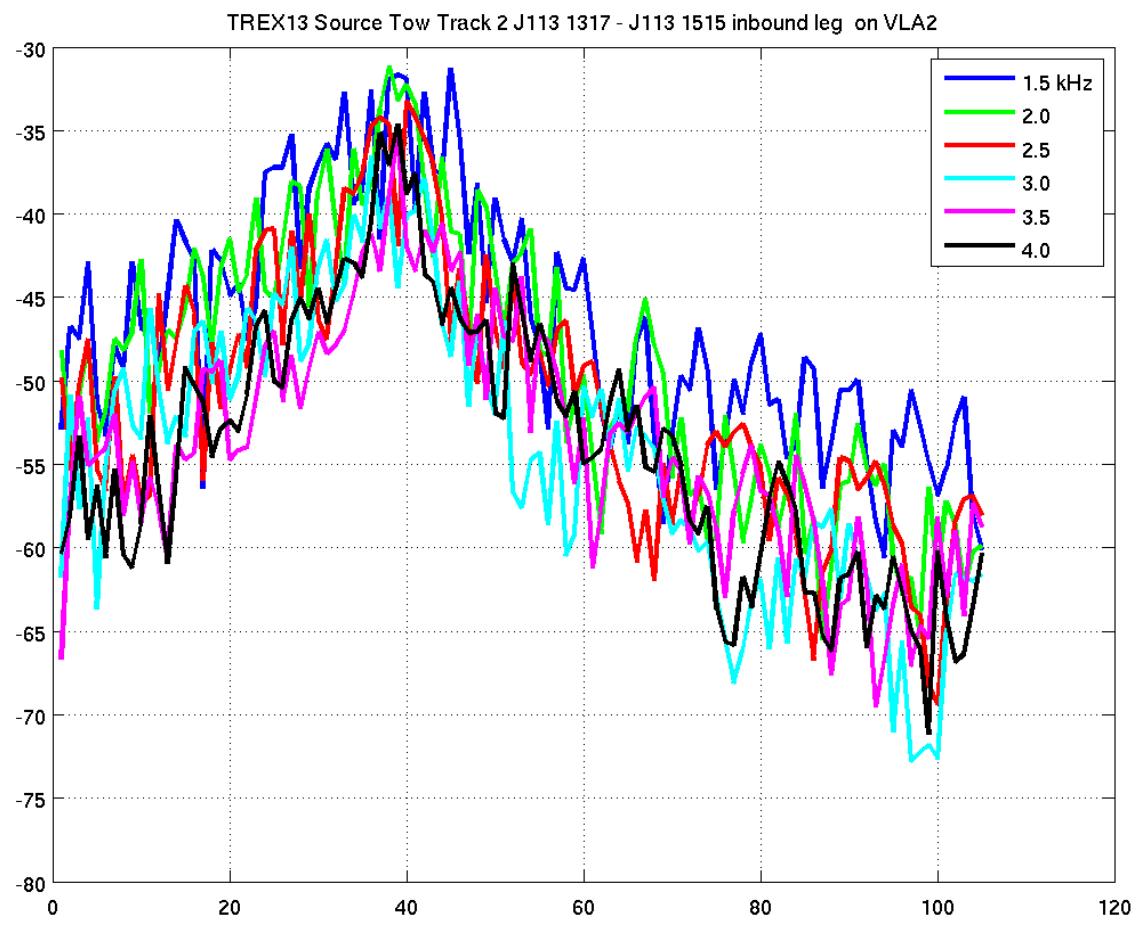

Figure 4. Transmission loss (dB) along inbound leg of source tow track Reverb Track 02. Horizontal axis is in increments of $30 \mathrm{~s}$. 